\title{
INOVAÇÃO DOS SUVENIRES DE GRAMADO: A PARTIR DE UM PROJETO DE DESIGN DE SUPERFÍCIE
}

Silvia Guimarães Costa

Programa de Pós Graduação em Design

Centro Universitário Ritter dos Reis

scosta816@gmail.com

Maria do Carmo Torri Dischinger

Programa de Pós Graduação em Design

Centro Universitário Ritter dos Reis

fabiane_wolff@uniritter.edu.br

Resumo: Com tantos produtos semelhantes oferecidos no mercado, os consumidores buscam cada vez mais objetos com significados. O suvenir é um objeto de memória com um grande potencial de exploração no mercado, uma vez que pode ser associado às experiências vivenciadas pelos turistas no local visitado a algo tangível, permitindo que os momentos do passado sejam transformados novamente no presente. A exploração do tema suvenir como proposta de projeto no campo do Design de Superfície é o ponto de partida desse artigo, que tem como objetivo principal proporcionar ao turista que visita Gramado um objeto de lembrança diferenciado e atrativo. Através de um levantamento teórico e uma pesquisa de campo em Gramado, foi desenvolvido o projeto, tendo como superfície explorada o chocolate e o uso de técnicas criativas aplicadas no design de superfície. Ao final do projeto, o novo visual trazido aos chocolates de Gramado dos principais pontos turísticos da cidade permitiu ampliar o conceito inovador do suvenir.

Palavras-chave: Suvenir; Chocolate; Design de Superfície.

\begin{abstract}
With so many similar products offered on the market, consumers are increasingly looking objects with meanings. The suvenir is an object of memory with a great potential in market exploitation, once it can associate the lived experiences of the place visited by tourists to something tangible, allowing moments of the past are to be transformed again in the present. The exploration of the theme souvenir as a project proposal in the field of Surface Design is the starting point of this article, which aims to provide the tourist that visites Gramado, an object of memory distinctive and attractive. Through a theoretical survey and field research in Gramado, the project was developed, having as object the chocolate surface and the use of creativity techniques applied in surface design. At the end of the project, the new look brought to Gramado's chocolates of the main sights of the city allowed to expand the innovative concept of suvenir.
\end{abstract}


Keywords: Suvenir. Chocolate. Surface Design.

\section{INTRODUÇÃO}

A superfície está em contato com o homem como meio de comunicação desde um passado remoto. No período Paleolítico da Pré-História e depois no Mesolítico o homem já fazia sinais gráficos de expressão simbólica na superfície das paredes das cavernas.

Segundo Manzini (1993), os objetos têm comunicado desde a Pré-História as referências culturais, a realidade, o caráter e a história do homem. Já existia uma preocupação do homem em comunicar a identidade de sua tribo, seus costumes, posição de hierarquia e hábitos de caça. Nesse sentido concorda Rüthschilling (2008) ao afirmar que para se comunicar o homem utilizava a repetição de traços e figuras.

Hoje com o avanço da tecnologia e diversidade de materiais, a superfície assume diversas funções, adquirindo outros desempenhos que vão além de sua função tradicional de proteção, acabamento e decoração, ao desempenho que a torna um meio de comunicação estática (superfícies impressas ou visuais) ou dinâmica (superfícies com estímulos sensoriais) (MANZINI, 1993).

Diante da quantidade de produtos muito semelhantes no que diz respeito às características técnicas, qualidade e preço, a experiência gerada pelo objeto pode ser considerada um forte meio para a diferenciação dos produtos no mercado (DESMET, 2003). Atualmente os consumidores estão à procura de outros aspectos nos produtos; além da boa funcionalidade e usabilidade, procuram objetos com significados subjetivos, que remetam aos lugares, momentos agradáveis ou pessoas especiais, trazidos pela sua interação com o objeto.

Com relação à experiência, existe um determinado produto muito conhecido no ramo do Turismo, o qual representa, em formato de objeto, as experiências consideradas intangíveis vivenciadas pelas pessoas em um determinado destino turístico. Este objeto é conhecido como suvenir (HORODYSKI, MANOSSO, GANDARA, 2012).

Cerreta (2005) afirma que o suvenir é estritamente importante ao turismo, pois gera um benefício econômico às pessoas que atuam e se envolvem neste tipo de comércio. O Turismo, no contexto socioeconômico, movimenta um fluxo de pessoas de um local para o outro trazendo renda, emprego e oportunidades, seja pelo aumento produzido na economia e/ou pelo envolvimento social.

Desse modo, evidencia-se a importância do suvenir para o desenvolvimento do Turismo de uma cidade ou país. Porém, conforme Machado e Siqueira (2008), este objeto de lembrança não tem sido o foco de investigação em trabalhos relacionados ao ramo do Turismo, como também considerado um objeto de desejo entre os turistas, uma vez que são conhecidos geralmente como objetos banais e de gosto duvidoso, segundo Horodyski, Manoso e Gandara, (2012). Identificando-se assim um possível campo de investigação, tanto na teoria quanto na prática, em projetos de Design de Superfície.

Para o desenvolvimento deste trabalho foi escolhido como tema principal o suvenir. O projeto detalhado no presente artigo consiste na criação de um novo suvenir para a cidade de Gramado, reconhecida como um dos pontos turísticos mais frequentados no estado do Rio Grande do Sul. 
O objetivo principal deste projeto é proporcionar ao turista que visita a cidade de Gramado um suvenir diferenciado e mais atrativo, utilizando como superfície o chocolate. Como objetivos secundários, melhorar a percepção do turista com relação à cidade através do objeto criado e aumentar a venda de suvenires.

\section{DESENVOLVIMENTO}

Com o objetivo de compreender melhor o contexto do projeto, esse capítulo é dividido em três subseções: "Suvenir, um objeto simbólico e de memória", onde se conceitua o tema do projeto, "Gramado destino turístico crucial na Serra Gaúcha", onde se apresenta o cenário para criação dos suvenires e os pontos turísticos escolhidos para o projeto e por último, "O Projeto", onde se apresenta a metodologia de pesquisa empregada no projeto de Design de Superfície e como se deu o desenvolvimento da criação dos novos suvenires.

\subsection{Suvenir: um objeto simbólico e de memória}

De acordo com Machado e Siqueira (2008) o turismo é um acontecimento onde se destaca o consumo de bens materiais ou imateriais, sendo o suvenir um dos principais produtos envolvidos nesta atividade.

O termo suvenir deriva do verbo francês souvenir que constitui a ação de lembrar; como substantivo no inglês significa um objeto de lembrança (SWANSON e TIMOTHY, 2012). Suvenir, ou souvenir ${ }^{1}$, é um objeto que representa os locais visitados pelo turista e que normalmente é adquirido para recordar as experiências vivenciadas por ele nestes espaços.

O suvenir está ligado ao turismo da cidade visitada, por isso é uma atividade que movimenta a economia, uma vez que traz benefícios às pessoas que atuam e se envolvem neste tipo de comércio, gerando renda, mais empregos e oportunidades.

Porém este objeto de lembrança não tem sido muito explorado em pesquisas científicas relacionadas ao Turismo, principalmente em pesquisas nacionais, onde existe certa resistência por parte dos pesquisadores brasileiros em utilizar o termo suvenir, conforme um levantamento bibliográfico sobre o tema (HORODYSKI, MANOSSO e GANDARA, 2012).

Dessa forma, revela-se o tema suvenir como um objeto de investigação. Este estudo é interessante não só pela função simbólica que esse objeto exerce de lembrar o local visitado, como a estátua da Torre Eiffel que o turista compra para lembrar que esteve em Paris, mas também por outras ligações referentes às experiências vivenciadas naquele local, como de conhecer alguém especial, um cheiro ou sabor novo. Por isso o suvenir pode transmitir a experiência vivenciada pelo turista, algo intangível, em um produto tangível, repleto de significados. Segundo Schimitt (2000, p. 74),

(...) experiências são acontecimentos individuais que ocorrem como resposta a algum estímulo. As experiências duram a vida toda. Geralmente são o resultado de uma observação direta e/ou de participação nos acontecimentos reais, imaginários ou virtuais.

\footnotetext{
${ }^{1}$ Os dois termos são aceitos na língua portuguesa, pois se referem ao mesmo conceito, porém, para o presente artigo é utilizado apenas a palavra suvenir para se referir ao objeto de lembrança.
} 
Segundo Swanson e Timothy (2012) o suvenir possui vários conceitos no estudo do Turismo. Ele pode ser classificado como: uma lembrança simbólica, um commodity qualquer, um commodity turístico e outros tipos de lembrança.

Este objeto pode ser uma lembrança simbólica de um evento ou de uma experiência intangível e momentânea. "Suvenires são às vezes descritos como metonímia de eventos, lugares ou experiências, imbuídos de significado e consequência." (SWANSON e TIMOTHY, 2012, p.490).

Mas também pode significar um commodity comum, encontrado em lojas e mercados de artesanato, com valor comercial, porém consumido com pouco valor emocional, ou um commodity turístico, uma mercadoria adquirida pelo visitante durante a viagem que causa uma memória de experiência.

Nesse trabalho os suvenires estudados são os objetos comprados ou consumidos intencionalmente como lembranças simbólicas. Assim como os produtos são constituídos de um simbolismo que lhes confere um valor superior ao seu valor monetário, o suvenir também é um objeto simbólico, portanto, possui significado.

Este significado é estabelecido pela forma de utilização que seu comprador dá a esse objeto. Sendo este valor simbólico de caráter subjetivo, ou seja, que muda de pessoa para pessoa, por exemplo, uma pessoa pode achar que a recordação da sua viagem à Gramado foi uma noite inesquecível que ela teve no Festival de Cinema, pois naquele dia ela apertou a mão de seu ator favorito, sendo a foto tirada e assinada por seu ídolo o suvenir de sua viagem, enquanto que para outra pessoa ter a estátua do Kikito em sua casa, prêmio do festival, representa a lembrança do Palácio dos Festivais que ela visitou.

Porém, existe algo em comum entre os vários significados que o suvenir pode ter: a lembrança. O turista enxerga o suvenir como uma relíquia para recordar sua experiência de viagem, ou como um mimo para mostrar a pessoa presenteada que ele se lembrou dela ao viajar, ou ainda para recordar alguma informação sobre o local visitado, como a cultura e história do lugar (MACHADO E SIQUEIRA, 2008).

O suvenir possui a função de concretizar a experiência passada através de um artefato real, exercendo o papel de um objeto de memória para a pessoa que visitou determinado destino turístico e quis carregar consigo uma lembrança dessa experiência.

Quando o suvenir é repassado das mãos do turista para as dos amigos ou familiares como presente tem a função de compartilhar com a pessoa presenteada a experiência daquele local, deste modo o suvenir permite narrar a história daquele local ou experiência do visitante à pessoa (MACHADO E SIQUEIRA, 2008).

Esse é um aspecto considerado muito importante para o turismo, uma vez que a divulgação do destino turístico por meio da entrega de suvenires como presente pode criar o desejo da visita ao local para quem ganha o objeto, aumentando assim a prática do turismo e consequentemente melhorando a economia do local.

Assim como as superfícies, os suvenires funcionam com um meio de comunicação, uma vez que possui o papel de expor ao turista as características do local visitado ou da cultura daquele lugar, como também, ao ser dado como presente, de transmitir uma mensagem à pessoa presenteada, seja essa afetiva, histórica ou simbólica.

Segundo Machado e Siqueira (2008) os habitantes dos lugares visitados pelos turistas também compartilham algo de si com os visitantes através do suvenir, 
estabelecendo uma troca de cultura entre os turistas e os anfitriões. A compra de um suvenir também pode estar vinculada ao status social conferido pelo objeto, uma vez que o suvenir comprova que a pessoa esteve em determinado local ao grupo a qual pertence. Os autores dizem que a viagem é vista como "um bem cultural na sociedade contemporânea que celebra o consumo." (MACHADO E SIQUEIRA, 2008).

Esse desejo de status pode ser percebido em viagens de colégios, como por exemplo, de uma turma de segundo grau que visita Bariloche, onde os alunos para mostrar que estiveram no Cerro Campanário aos amigos tiram e compram fotos com o cão São Bernardo, ou, no Cristo Redentor em uma viagem ao Rio de Janeiro, pontos turísticos considerados tradicionais para quem visita esses locais.

Através desse objeto de memória o turista pode se lembrar de uma experiência turística acontecida no passado por meio do momento presente, podendo essa lembrança ser momentânea; no caso de um suvenir ligado a gastronomia como, por exemplo, um chocolate, ou contínua; como a imagem de um cartão postal, a qual dura mais tempo. Em ambas as situações a realização pessoal do turista com relação a sua compra deve-se ao valor simbólico do suvenir.

Nesse contexto, criar suvenires que tenham significados para os turistas podem trazer experiências mais ricas e aumentar o interesse deles em conhecer o local visitado mais vezes ou de indicar a viagem aos amigos e parentes, ajudando assim no desenvolvimento do turismo da cidade.

Depois de explorado o tema suvenir, a seguir é apresentado de forma breve o cenário de estudo para esse projeto, a cidade de Gramado, considerada um dos destinos do Brasil mais frequentados pelos turistas.

\subsection{Gramado: destino turístico crucial na Serra Gaúcha}

Gramado está localizada no coração da serra gaúcha, à $115 \mathrm{~km}$ de Porto Alegre, capital do Rio Grande do Sul. A cidade é conhecida por sua vocação para o turismo, estando em terceiro lugar no ranking como destino turístico nacional preferido, conforme uma pesquisa realizada pela Fundação Getúlio Vargas - FGV (VOLK, 2009). A cidade também é vista pelo Governo Federal como um dos 65 Destinos Indutores do desenvolvimento do Turismo, visto que $90 \%$ da receita de Gramado é proveniente da atividade turística, conforme site oficial da Prefeitura Municipal da cidade (PREFEITURA DE GRAMADO, 2007).

Em 2012, de acordo com a mensuração feita pela Secretaria de Turismo de Gramado, com base no trânsito de veículos nas praças de pedágios concessionadas pela Brita Rodovias, 5.271 milhões de visitantes passaram pelo local. Confirma-se assim que para os turistas que visitam a Serra Gaúcha, sejam eles do estado ou não Gramado é considerado um destino turístico imperdível de se visitar.

As paisagens naturais serranas, com a presença de florestas de araucárias, diversidade de flores, animais silvestres, fazem parte da beleza natural encontrada em Gramado. Além dos atrativos naturais, a cidade possui uma ampla e qualificada infraestrutura acolhedora para receber os seus visitantes, que procuram na cidade não só desfrutar de um momento de descanso e lazer, mas também como local para a realização de encontros, congressos e eventos de diversas categorias (MOLLING, 2007).

Outro destaque da cidade são os eventos culturais que ela oferece: o Natal Luz, Festival de Cinema, Festa da Colônia, Festival de Gastronomia, Festival de Publicidade, 
Festival do Turismo e Páscoa em Gramado. Esta breve apresentação dos atrativos da cidade justificam a escolha de Gramado como cenário para esse trabalho.

Para a criação do projeto de design de superfície proposto, alguns pontos turísticos da cidade são escolhidos para serem explorados como fonte de referência no processo criativo do projeto. Para a escolha dos pontos turísticos a serem trabalhados ao longo do projeto a autora realizou uma viagem de campo a fim de vivenciar a experiência do turista que visita Gramado.

Foram visitados no total de nove pontos turísticos da cidade, porém ao fazer um levantamento sobre os principais suvenires que são vendidos nas lojas do centro da cidade, alguns pontos turísticos se destacam, são eles: os pórticos da entrada da cidade, a igreja São Pedro, o Palácio dos Festivais e o Lago Negro. Nesse contexto, a seguir são apresentados resumidamente os quatro pontos turísticos escolhidos para serem utilizados no projeto e os suvenires encontrados dos mesmos.

O Pórtico da entrada Nova Petrópolis é conhecido como uma das "entradas de boas vindas" da cidade, local muito frequentado pelos turistas para tirar fotografia como lembrança de Gramado. Possui uma arquitetura com estilo bávaro nos telhados com franjas, rodeado de belos jardins e flores.

No local não existe um objeto vendido como suvenir, apenas a distribuição de folders e materiais impressos explicativos da cidade. Porém, ao andar pelas diversas lojas da cidade encontram-se alguns suvenires que simbolizam o Pórtico da entrada da cidade, este é representado em forma de chaveiro, mini estátuas, termômetro, imã, entre outros objetos.

O Lago Negro possui este nome devido à presença de árvores importadas da Floresta Negra da Alemanha que rodeiam um lago verde escuro e profundo, cercado de pinheiros altos e de flores, como as azaleias no inverno e as hortênsias no verão.

Além da paisagem magnífica, outra atração que desperta curiosidade dos visitantes desse local são os pedalinhos, onde o turista pode desfrutar de toda a paisagem sozinho ou acompanhado, pedalando no lago num tipo de carrinho flutuante com o formato de um cisne, símbolo clássico deste ponto turístico.

Ao contrário do Pórtico, nesse local encontram-se alguns suvenires para venda, como: roupas e bonés, chaveiros, cartões postais e chocolates, onde na embalagem consta o nome e imagem do local. Mas ao andar pela cidade existem outros suvenires que representam o Lago Negro no comércio, como canecas, copinhos de cachaça, caixa de chocolates com a imagem do pedalinho e garrafinha de água.

A Igreja São Pedro é conhecida como uma das maiores manifestações religiosas da população da cidade ao seu padroeiro, São Pedro. Ao sair da igreja, o turista depara-se com a loja Casa São Pedro, onde pode encontrar alguns objetos de lembrança, como canecas, chaveiros, retrato da igreja e também santinho, terço, retrato e réplica do padroeiro São Pedro. Em lojas no centro da cidade, ele também pode obter os mesmos suvenires.

O Palácio dos Festivais possuiu um edifício com estilo colonial localizado bem no centro da cidade, onde acontece um dos eventos mais esperados do ano pelos 
turistas, o Festival de Cinema de Gramado, evento cinematográfico muito famoso no Brasil que ocorre no mês de agosto.

Seu prédio é conhecido pela famosa arquitetura típica de Gramado inspirada no estilo Baváro, em sua calçada há diversos símbolos que remetem ao festival, como o formato do Kikito, uma estrela e a gravação das mãos dos famosos. Como suvenires desse ponto turístico há canecas, chaveiros e estátuas em chocolates que simbolizam o Kikito, visto como o símbolo do Festival de Cinema.

\subsection{O Projeto}

Para compreensão do tema escolhido e levantamento teórico utilizou-se da pesquisa documental, de campo e bibliográfica. Para o desenvolvimento do projeto de design de superfície do novo suvenir para cidade de Gramado foram analisadas algumas metodologias, e para melhor eficácia do projeto deste trabalho, optou-se em unir algumas etapas de diferentes métodos.

Utilizou-se das metodologias dos seguintes autores: Munari (1998), Gomes (2004) e Bonsiepe (1984). A seguir, são apresentadas as etapas escolhidas de cada metodologia.

De acordo com a metodologia de Munari (1998), a problematização do projeto a ser desenvolvido por um designer deve ser divido em:

1) Definição do problema: Como desenvolver um novo suvenir para cidade de Gramado, explorando a linguagem do Design de Superfície.

2) Componentes do problema:

- Que tipo de objeto deve ser criado como suvenir;

- Como vincular o suvenir aos principais pontos turísticos da cidade;

- Quais características devem ser levadas em consideração para criação do desenho da superfície a fim de tornar o suvenir um objeto mais desejável pelos turistas.

3) Coleta e Análise de dados: No projeto em questão realizou-se uma pesquisa de campo para coleta de materiais relevantes para o projeto. Através dessa pesquisa, comentada no capítulo anterior, obtiveram-se informações e imagens ricas em detalhes que, aos serem analisadas permitiu definir algumas questões para o projeto:

- Superfície-objeto do suvenir: chocolate de Gramado.

- As características simbólicas dos pontos turísticos escolhidas serão trabalhadas através de técnicas de criatividade e sistema de repetição aplicada no Design de Superfície.

- Para tornar o suvenir um objeto mais desejável pelos turistas serão utilizadas na composição do desenho da superfície elementos abstratos e figurativos, como também contornos mais suaves a fim de tornar o desenho mais sofisticado e bonito. 
Como o processo criativo de Gomes (2004) também foi baseado na metodologia de Gui Bonisepe (1984), ambas as etapas se assemelham. Entende-se que a metodologia em um projeto de design serve para auxiliar o designer no desenvolvimento do projeto, por isso, entre as fases apresentadas na metodologia de Bonsiepe (1984), para a criação do novo suvenir não se achou necessário realizar todas as etapas sugeridas pelos autores.

Assim, foram escolhidas apenas as etapas que certamente devem contribuir para o projeto proposto, que são: Preparação, Esquentação, lluminação e Elaboração.

4) Preparação: Nessa etapa, foram desenvolvidas as análises sincrônica e funcional por serem consideradas as mais relevantes para este projeto. Através da análise sincrônica do chocolate de Gramado foi escolhido o formato de bombom para o suvenir proposto neste projeto, feito de chocolate ao leite. Ao realizar a análise funcional dos chocolates, foi notado que as funções que mais se destacam no chocolate de Gramado e que devem ser levadas em consideração no projeto são a estética e a simbólica.

5) Esquentação ou Geração de alternativas: A partir da análise das imagens tiradas pela autora na pesquisa de campo dos quatros pontos turísticos, foram escolhidos alguns elementos para se criar os motivos que irão compor os desenhos da superfície.

Os motivos foram construídos através do estudo dos elementos selecionados, aplicando dois tipos de operações: relações grupais entre os elementos, de união, superunião e hiperunião dos elementos, e operações elementares de superposições, como de translação, rotação, reflexão e dilatação. Para a geração de alternativas foram integradas aos elementos gráficos as operações de superposições com as relações grupais, sugeridas por Bonsiepe (1984) e Gomes (2004).

Para definir o tamanho do módulo da estampa, foi retomada uma das questões problema levantada no início do projeto, tornar o suvenir mais interessante para o turista. Pensando na embalagem em forma de caixa na qual geralmente os chocolates são vendidos nas principais lojas de Gramado, teve-se a ideia de dividir o formato da embalagem em nove bombons que juntos formam uma imagem relacionada a um dos pontos turísticos da cidade.

6) Iluminação: Após geradas as alternativas, foram escolhidas os oito padrões para a coleção dos novos chocolates suvenires de Gramado. A coleção é formada por quatro suvenires referentes aos pontos escolhidos no projeto, estes são: Festival do Glamour, Pórtico das Boas Vindas, Lago dos Cisnes e Encontro Divino, sendo que cada suvenir possui dois padrões diferentes para o turista escolher.

7) Elaboração: Por se tratar de um suvenir, a estampa foi criada com a intenção de recordar cada ponto turístico, mesmo de forma subjetiva, por isso para a escolha de cores foram criados painéis semânticos referentes a cada ponto escolhido, de onde foi possível retirar uma combinação de até nove cores para cada padrão.

A seguir é apresentada a coleção dos novos chocolates suvenires de Gramado com suas respectivas cores aplicadas em cada padrão de suas quatro linhas, demonstradas nas figuras 1, 2, 3 e 4 abaixo. 


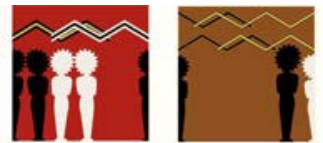

Bombons

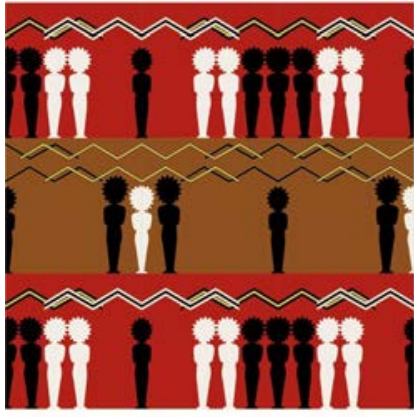

Padrão 1

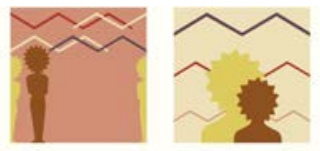

Bombons

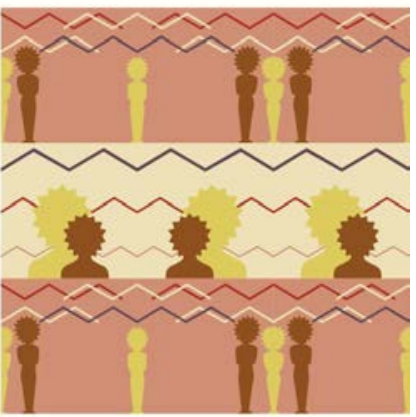

Padrão 2

Figura 1 - Padrões da linha Festival do Glamour

Fonte: Elaborado pela autora, com base na pesquisa realizada.

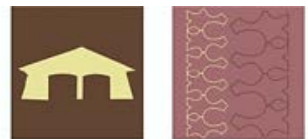

Bombons

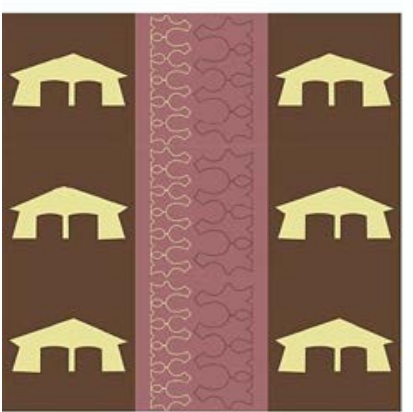

Padrāo 1
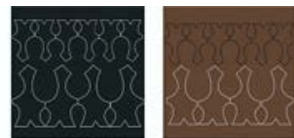

Bombons

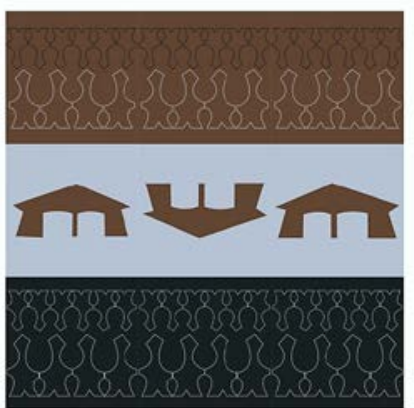

Padrāo 2

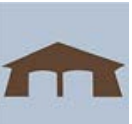



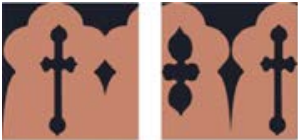

Bombons

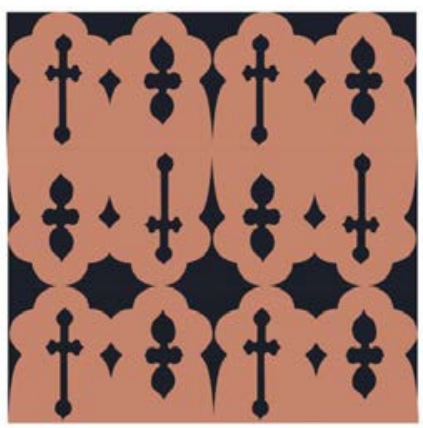

Padrão 1
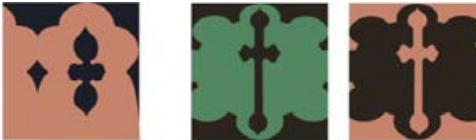

Bombons

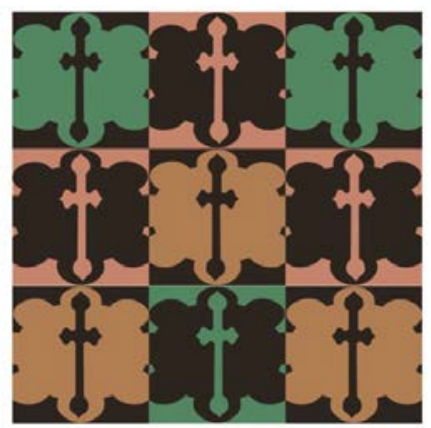

Padrão 2

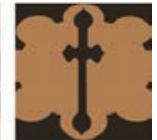

(1)

Fonte: Elaborado pela autora, com base na pesquisa realizada.

Depois de criada a coleção dos chocolates suvenires de Gramado foram feitas provas de impressão em offset para avaliar a espessura do contorno das figuras e as cores antes da confecção do protótipo. Como protótipo final foi prevista a confecção de 36 bombons de chocolate ao leite, de tamanho real, $4 \times 4 \mathrm{~cm}$. Para a produção dos mesmos foi escolhido apenas dois padrões da coleção de suvenires.

Por se tratar de um desenho rico em detalhes e cores, para a aplicação do desenho criado no bombom optou-se pelo emprego da impressão por Transfer, técnica manual muito utilizada na decoração de bombons, tortas e doces de chocolate.

\section{CONCLUSÃO}

Através de um levantamento teórico ao longo deste trabalho sobre o tema suvenir, foi possível compreender o quanto este objeto de memória é importante para a atividade do turismo, mas também o quanto ele ainda pode ser explorado em outras áreas, como a do Design de Superfície.

Ao realizar uma análise sincrônica dos suvenires oferecidos aos turistas nos principais pontos turísticos da cidade de Gramado, encontrou-se uma repetição de objetos comuns, com pouca originalidade e criatividade para despertar o interesse pela compra.

Ao se deparar com esse cenário, percebeu-se a oportunidade de criar um novo suvenir para cidade de Gramado através de um projeto de Design de Superfície. Optou-se pelo chocolate como superfície-objeto por ter sido descoberto, ao longo da pesquisa, que apesar do chocolate de Gramado ser muito comprado pelos visitantes, principalmente para ser levado como recordação da viagem, este possui pouca ligação com os pontos turísticos da cidade.

Na visitação de cada ponto, encontrou-se a inspiração para geração de ideias, e com o uso das técnicas de criatividade e sistema de repetição aplicadas no projeto, foi possível criar um novo propósito para os chocolates de Gramado: como suvenires dos pontos turísticos da cidade. O resultado foi a criação de uma Coleção de bombons 
formada por oito diferentes padrões que se referem aos quatros principais pontos visitados pelos turistas.

Além de proporcionar um novo visual aos chocolates de Gramado, o incremento do projeto com a formação de cada padrão pela junção de nove bombons, trouxe uma inovação aos suvenires e chocolates, uma vez que podem despertar a curiosidade e atenção dos consumidores, atendendo assim ao objetivo principal deste trabalho, de criar um suvenir mais atrativo e diferenciado para ser vendido aos visitantes da cidade.

Como futuras contribuições para este projeto, propõe-se adaptar os padrões da coleção a outros formatos de chocolates vendidos na cidade, como barras e pastilhas, a fim de ampliar os produtos da coleção. Como analisar novas propostas para a composição dos padrões criados, como a possibilidade de se criar multimódulos ou módulos recombináveis.

\section{REFERÊNCIAS}

BONSIEPE, G. Metodologia Experimental: Desenho Industrial. Brasília:

CNPQ/Coordenação Editorial, 1984.

CERRETA, Caroline Ciliane. A composição do gasto turístico nos municípios de Canela e Gramado. Estudo \&Debate. Lajeado, v. 12, n.2, p.59-74, 2005.

DESMET, P. A multilayered model of product emotions. The Design Journal, v. 6, Issue 2, p. 4-13, 2003.

GOMES, S. L. Criatividade: projeto <desenho> produto. Santa Maria: sCHDs, 2004.

HORODYSKI , G. S.; MANOSSO , F.C; GANDARA , J.M.G. 0 consumo de souvenirs e a experiência turística em Curitiba (PR). Caderno Virtual de Turismo. Rio de Janeiro, v. 12, n. 3, p.323-342, dez.2012.

HORODYSKI , G. S.; MANOSSO , F.C; GANDARA , J.M.G. A pesquisa narrativa na investigação das experiências turísticas relacionadas ao consumo de souvenirs: uma abordagem fenomenológica. Congresso Latino-Americano de Investigação Turística. São Paulo, ed.5, p.1-21, set.2012.

LOBACH, Bernd. Design industrial: bases para a configuração dos produtos industriais. São Paulo: E. Blucher, 2001.

MACHADO, P.S. e SIQUEIRA, E.D. Turismo, Consumo e Cultura: significados e usos sociais do suvenir em Petrópolis-RJ. Revista Contemporânea, v.1, n.10, 2008

MANZINI, Ezio. A matéria da invenção. Tradução de Pedro Afonso Dias. Lisboa: Centro Português de Design, 1993.

MUNARI, Bruno. Das coisas nascem coisas. São Paulo, SP: Martins Fontes, 1998 PREFEITURA MUNICIPAL DE GRAMADO. Gramado escolhido destino Indutor do turismo Nacional. Portal da prefeitura muncipal de Gramado do Rio Grande do Sul. 2007. Disponível em: <http://www.gramado.rs.gov.br/index.php/Turismo/Gramadoescolhido-destino-Indutor-do-turismo-Nacional.html>. Acesso em: 21 set. 2011.

RÜTHSCHILLING, E. A. Design de Superfície. Porto Alegre: Ed. Da UFRGS, 2008. 
SCHIMITT, Berned H. Marketing experimental. São Paulo: Nobel, 2000.

SWANSON, K.K; TIMOTHY, D.J. Souvenirs: Iconsofmeaning, commercialization and commoditization. 2012: Tourism Management, v. 33, p.489-499.

VOLK, Rosa Helena. Gramado, coração da Serra Gaúcha. Disponível em <http://www.gramado.rs.gov.br/index.php/es/Turismo/Gramado-coracao-da-SerraGaucha.html > Acesso em: 23 out. 2013. 